\title{
Das neue internationale Privatrecht von Venezuela
}

\author{
Unter besonderer Berücksichtigung des Wohnsitzes
}

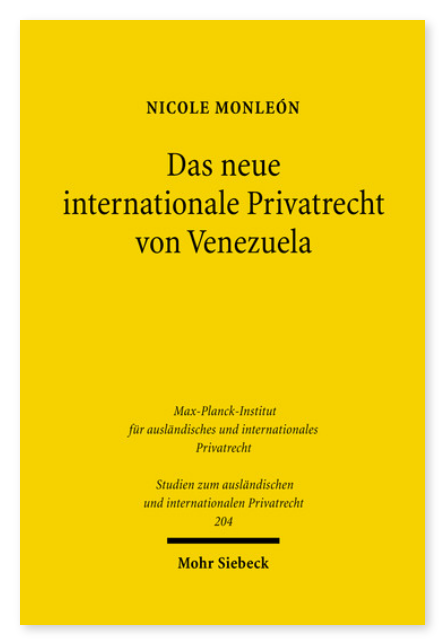

2008. XIX, 316 Seiten. StudIPR 204

ISBN 978-3-16-151389-3

DOI 10.1628/978-3-16-151389-3

eBook PDF 79,00€

ISBN 978-3-16-149722-3

fadengeheftete Broschur 79,00€
Nicole Monleón befaßt sich mit dem gegenwärtigen venezolanischen internationalen Privat- und Verfahrensrecht. Sie beginnt mit einem kurzen Rückblick auf die Rechtsgeschichte Venezuelas und zeichnet die Entwicklung des venezolanischen Kollisionsrechts auf nationaler und staatsvertraglicher Ebene nach. Im Anschluss daran kommentiert sie die im Februar 1999 in Kraft getretene Ley de Derecho Internacional Privado (LDIP). Dieses erste IPR-Gesetz löst den für das venezolanische Kollisionsrechtssystem zuvor charakteristischen Widerstreit zwischen den Prinzipien der Territorialität und Personalität der Gesetze auf. Zudem erfährt das venezolanische internationale Privat- und Zivilverfahrensrecht erstmals eine zusammenhängende und inhaltlich ausgewogene Regelung. Die Autorin stellt die Entstehungsgeschichte der LDIP, ihre Leitgedanken und Ziele sowie ihre Struktur dar. Ebenso zeigt sie Zusammenhänge zwischen der venezolanischen Novelle und weltweit anzutreffenden Tendenzen auf. Die ausführliche Kommentierung der Regelungen des Allgemeinen und Besonderen Teils des internationalen Privatrechts und des internationalen Zivilverfahrensrechts erfolgt unter Auswertung der Gesetzesmaterialien, Rechtsprechung und Lehre. Die wichtigste Neuerung der LDIP ist die uneingeschränkte Einführung des Wohnsitzprinzips. Die Autorin richtet ihren Fokus daher auf die Auslegung des kollisionsrechtlichen Wohnsitzbegriffs, der in der LDIP mit dem gewöhnlichen Aufenthalt legaldefiniert wird. Die Auslegung setzt bei der Entstehungsgeschichte der Novelle an und erfolgt auf rechtsvergleichender Basis.

Nicole Monleón Geboren 1975; Studium der Rechtswissenschaften in Hamburg; 2008 Promotion; Legal Counsel bei der Panasonic Marketing Europe $\mathrm{GmbH}$.
Jetzt bestellen:

https://mohrsiebeck.com/buch/das-neue-internationale-privatrecht-von-venezuela-9783161513893?no_cache=1 order@mohrsiebeck.com

Telefon: +49 (0)7071-923-17

Telefax: +49 (0)7071-51104 